\title{
Percutaneous Microwave Ablation of Stage T1b Renal Cell Carcinoma: Short-Term Assessment of Technical Feasibility, Short-Term Oncologic Outcomes, and Safety
}

\author{
Jianhai Guo, MD ${ }^{1,2}$ and Ronald S. Arellano, MD ${ }^{1}$
}

\begin{abstract}
Purpose: To report on the safety, technical results, and oncologic outcomes of computed tomography guided percutaneous microwave ablation of stage cT1b renal cell carcinoma.

Materials and Methods: This single-center retrospective study investigated consecutive patients with T1b renal cell carcinoma who were treated with CT guided percutaneous microwave ablation between December 2015 and May 2019. Patient baseline characteristics, tumor biologic features, technical parameters, clinical outcomes, and complications were recorded and evaluated. Local tumor progression-free survival and overall survival rates were estimated using the Kaplan-Meier methods.

Results: This study included 23 patients (18 men [mean age \pm standard deviation, 74.6 years \pm 10.2 ; range 58-89 years] and 5 women [mean age, 71.6 years \pm 10.1 ; range $62-86$ years]; overall mean age, 74.0 years \pm 10.0 ; range 58-89 years) with $23 \mathrm{~T} 1 \mathrm{~b}$ renal cell carcinomas. Primary technical success was achieved in 20/23 (87\%) patients. Secondary technical success was achieved in 3/3 (100\%) patients. Local tumor progression-free survival was $100.0 \%, 90.9 \%$, and $90.9 \%$ at 1,2 , and 3 years, respectively. Overall survival was $95.2 \%, 85.7 \%$, and $71.4 \%$ at 1 , 2 , and 3 years, respectively. There were $2(8.7 \%)$ complications; both were classified as minor complications according to the Society of Interventional Radiology grading system.

Conclusions: Computed tomography guided percutaneous microwave ablation for T1b renal cell carcinoma is associated with high rates of technical success, excellent local tumor progression-free survival, short-term survival and overall survival, and low complication rates.
\end{abstract}

Keywords: microwave ablation, renal cancer, T1b

\section{Introduction}

$\mathbf{T}$ HE INCIDENCE OF small renal cell carcinoma (RCC) worldwide has increased in recent decades due to advances in abdominal imaging techniques and an aging population. ${ }^{1,2}$ While partial nephrectomy (PN) is considered standard treatment for early-stage renal tumors, minimally invasive thermal ablation is a therapeutic option in select patients with early stage RCC, particularly in patients with significant comorbidities or those who are reluctant to undergo surgery. ${ }^{3}$ Radiofrequency ablation (RFA) and cryoablation (CA) are the two most commonly used ablative technologies and have shown good clinical results in treating T1a renal tumors. $^{4,5}$ The American Urological Association currently recommends consideration of percutaneous thermal ablation with RFA and CA as alternative options to PN, radical nephrectomy (RN), or active surveillance for cT1a tumors $<3 \mathrm{~cm}$. The same guidelines do not currently recommend percutaneous thermal ablation as an option for patients with T1b tumors, due to concerns of higher risk of recurrence or treatment failure., While some emerging reports suggest that RFA and CA may be effective for $\mathrm{T} 1 \mathrm{~b}$ tumors, ${ }^{7,8}$ the role of microwave ablation (MWA) for treatment of T1b tumors remains unclear. ${ }^{9}$ The purpose of this study was to report on the safety, technical results, and short-term oncologic outcomes of computed tomography (CT) guided percutaneous MWA of stage T1b RCC.

\footnotetext{
${ }^{1}$ Division of Interventional Radiology, Department of Radiology, Massachusetts General Hospital, Boston, Massachusetts, USA.

${ }^{2}$ Department of Interventional Therapy, Key Laboratory of Carcinogenesis and Translational Research (Ministry of Education/Beijing), Peking University Cancer Hospital and Institute, Beijing, China.

The material in this article was not presented at SIR Annual Scientific Meeting.
} 


\section{Materials and Methods}

The institutional review board approved this Health Insurance Portability and Accountability-compliant study.

\section{Patients}

An institutional database was used to retrospectively identify 23 adult patients with 23 biopsy-proven clinical stage T1b RCCs who were treated with CT-guided percutaneous MWA between December 2015 and May 2019 in our institution. All patients were seen in Urology and Interventional Radiology clinic and counseled on all treatment options, including PN, RN local thermal ablation, and surveillance. The decision to pursue thermal ablation was by consensus decision by Urology, medical oncology, and interventional radiology. The decision to use MWA, as opposed to other thermal ablative options, was at the discretion of interventionist performing the procedure. Before the ablation, the interventional radiologist reviewed preprocedure cross-sectional imaging to determine desired size of the zone of ablation based on tumor size and to determine whether a single or overlapping ablations were needed to create the planned ablation zone. In general, power settings of Watts and time were selected based on manufacturer recommendations that would create a zone of ablation that encompassed the tumor and extended a minimum of $5 \mathrm{~mm}$ beyond the tumor margins. In addition, preablation review of imaging was performed to determine if bowel was within $5 \mathrm{~mm}$ of the tumor margin in anticipation of possible hydrodissection to displace the bowel away to minimize the risk of nontarget organ injury, as previously described. ${ }^{10}$ Similarly, if preprocedure imaging documented that the tumor was within $4 \mathrm{~mm}$ of the central collecting system, the procedures were planned to a Urologist present on the procedure day for temporary ipsilateral ureteral stent placement for pyeloperfusion during treatment, based on a previously reported technique for RFA of central RCC. ${ }^{11}$ The number of cases in which hydrodissection and/or pyeloperfusion were used was recorded.

\section{MWA procedures}

All MWAs were performed by a board-certified interventional radiologist with more than 22 years of experience in image-guided percutaneous thermal ablation of renal masses. All ablations were performed using CT guidance (16-slice Lightspeed; GE Medical Systems, Madison, WI). MWAs were performed using a 14-gauge antenna that operates at $2.45 \mathrm{GHz}$ (AMICA ${ }^{\mathrm{TM}}$; HS Medical, Boca Raton, FL). Patients were treated with monitored anesthesia care. The number of overlapping ablations was mainly dependent on tumor size, tumor location, and expected margins. The goal of all ablations was to create a circumferential ablative margin of at least $5 \mathrm{~mm}$ around the tumor. An immediate postprocedure unenhanced CT scan was performed to assess for immediate treatment response and periprocedural complications. Adjuvant methods of hydrodissection with dilute contrast $\left(20 \mathrm{~mL}\right.$ Isovue ${ }^{\circledR} 300$ [Bracco Diagnostics, Monroe Township, NJ], in $1000 \mathrm{~mL}$ of $0.9 \%$ saline) or pyeloperfusion with a $5 \mathrm{~F}$ ureteral stent were performed to minimize the potential risk of nontarget injury to adjacent structures. Tumor volumes before and after ablation were calculated according to the formula: $V=1 / 2\left(\right.$ length $\times$ width $^{2}$ ). After treatment, all patients underwent nursing observation for 2-4 hours before discharge from the hospital.

\section{Follow-up}

The first imaging follow-up with contrast material enhanced CT or MRI was performed $\sim 4$ weeks after MWA to assess technique efficacy and to evaluate for complications. Thereafter, patients were reevaluated with CT or MRI at $\sim 6$ month intervals for 2 years, then yearly thereafter. Postprocedural measures included technical efficacy, complications, and local recurrence.

\section{Data collection}

Patient demographics (age, sex, race, body mass index, and Charlson comorbidity index), procedural data, complications within 30 days, technique efficacy, and survival were evaluated. The Charlson comorbidity index was adjusted for age. ${ }^{12}$ Based on preablation imaging, tumor complexity was graded according to tumor size, location, involvement of the renal sinus, and nearness to collecting system (Radius, Exophytic/Endophytic, Nearness to the collecting system, Anterior/posterior, Location relative to the polar lines [R.E.N.A.L.] score and Preoperative Aspects and Dimensions Used for an Anatomical [PADUA] score). ${ }^{13,14}$ Complications were classified from A to F based on the Society of Interventional Radiology grading system. ${ }^{15}$ Pre- and postprocedure estimated glomerular filtration rate was recorded.

\section{Definition of terminologies}

Terminologies used to evaluate the treatment outcomes and complications of MWA were based on previously published classification guidelines. ${ }^{16}$ Technical success of MWA was effective completion of the ablation as planned. Oncologic outcomes included local tumor progression-free survival and overall survival (OS). Local tumor progression was defined as the appearance of a new tumor with enhancement or the enlargement of the ablated tumor within the ablation zone.

\section{Statistical analyses}

Categorical variables were summarized as frequencies and percentages. Continuous variables were expressed as means and standard deviations or medians with ranges. A two-tailed two related samples nonparametric test was used to compare pre- and postablation tumor volumes. One-way analysis of variance or nonparametric test was used to compare ablation protocol and clinical results between different tumor complexities according to the R.E.N.A.L. score and PADUA scores, respectively. The Kaplan-Meier method was used for local tumor progression-free survival and OS analyses. A $p$ value of $<0.05$ was considered indicative of a significant difference for all statistical tests. Statistical analyses were performed using the SPSS software program (version 22; IBM SPSS Statistics).

\section{Results}

\section{Patient baseline characteristics and procedure data}

A single MWA antenna was used to perform all ablations. Single-session treatments were performed in 19/23 (82.6\%) patients, and two-session treatments were performed in $4 / 23$ 
$(17.4 \%)$ patients. Of the 23 patients, $21(91.3 \%)$ had biopsy in a separate procedure before the ablation, and $2 / 23(8.7 \%)$ patients were performed biopsy in the same procedure as the ablation. Demographic and clinical characteristics are summarized in Table 1. The median number of overlapping treatments was 3 (range 1-8). The median duration of every overlapping power application was 10 minutes (range 1-15 minutes), and the median generator output power was $60 \mathrm{~W}$ (range 40-80 W).

Mean tumor size was $5.2 \mathrm{~cm}$ (range $4.1-6.6 \mathrm{~cm}$ ). Median tumor volumes were $42.0 \mathrm{~cm}^{3}$ (range $21.5-120.6 \mathrm{~cm}^{3}$ ) before ablation and $37.3 \mathrm{~cm}^{3}$ (range $9.4-141.5 \mathrm{~cm}^{3}$ ) after the last

Table 1. Demographic and Clinical Characteristics $(N=23)$

Characteristic Value

Age (years), mean $\pm \mathrm{SD}$ $74.0 \pm 10.0$

Sex, $n(\%)$

Male

$18(78.3)$

Female

5 (21.7)

Body mass index $\left(\mathrm{kg} / \mathrm{m}^{2}\right)$, median (range)

Charlson comorbidity index, median (range)

R.E.N.A.L. score, median (range)

PADUA score, median (range)

Kidney, $n(\%)$

Right kidney

Left kidney

Tumor diameter $(\mathrm{cm})$, mean $\pm \mathrm{SD}$

$31.0(19.8-54.2)$

Histologic RCC subtype, $n(\%)$

Clear cell

Papillary

$8(4-13)$

$8(5-10)$

$9(7-13)$

$11(47.8)$

$12(52.2)$

$5.2 \pm 0.9$

$19(82.6)$

4 (17.4)

Chronic kidney disease stage, $n(\%)$

$<3$

$3 \mathrm{~A}$

3B

4

5

$2(8.7)$

$5(21.7)$

$13(56.5)$

$2(8.7)$

$1(4.3)$

Coronary artery disease, $n(\%)$

No

$17(73.9)$

$6(26.1)$

Diabetes mellitus, $n(\%)$

No

$21(91.3)$

$2(8.7)$

Hypertension, $n(\%)$

No

Yes

$22(95.7)$

Heart failure, $n(\%)$

No

Yes

$20(87.0)$

$3(13.0)$

Preablation tumor volume $\left(\mathrm{cm}^{3}\right)$, median $42.0(21.5-120.6)$ (range)

Postablation tumor volume $\left(\mathrm{cm}^{3}\right)$, median (range)

$37.3(9.4-141.5)$

Ancillary procedures, $n(\%)$

Hydrodissection

Pyeloperfusion

$11(47.8)$

$3(13.0)$

PADUA = preoperative aspects and dimensions used for an anatomical; R.E.N.A.L. = Radius, Exophytic/Endophytic, Nearness to the collecting system, Anterior/posterior, Location relative to the polar lines; $\mathrm{RCC}=$ renal cell carcinoma; $\mathrm{SD}=$ standard deviation. imaging follow-up, respectively. The tumor volume after ablation was significantly smaller than that before ablation $(Z=-2.833, p=0.005)$.

\section{Follow-up}

Technical success was achieved in all 23 tumors (100\%). The median follow-up time was 16.6 months (range 1.5-43.5 months).

\section{Oncologic efficacy}

Primary technique efficacy was achieved in 20/23 (87.0\%) patients (Fig. 1). Three patients $(13.0 \%)$ with residual disease that was first identified at the 1-month follow-up imaging evaluation were retreated, with secondary technique efficacy of $100 \%$. No cases of metastatic disease or ablation-related deaths were identified. Four patients died from non-RCC related causes. Local tumor progression was identified in one patient at 17.5 months after the procedure. The 1-, 2-, and 3year local tumor progression-free survival was $100.0 \%, 90.9 \%$,
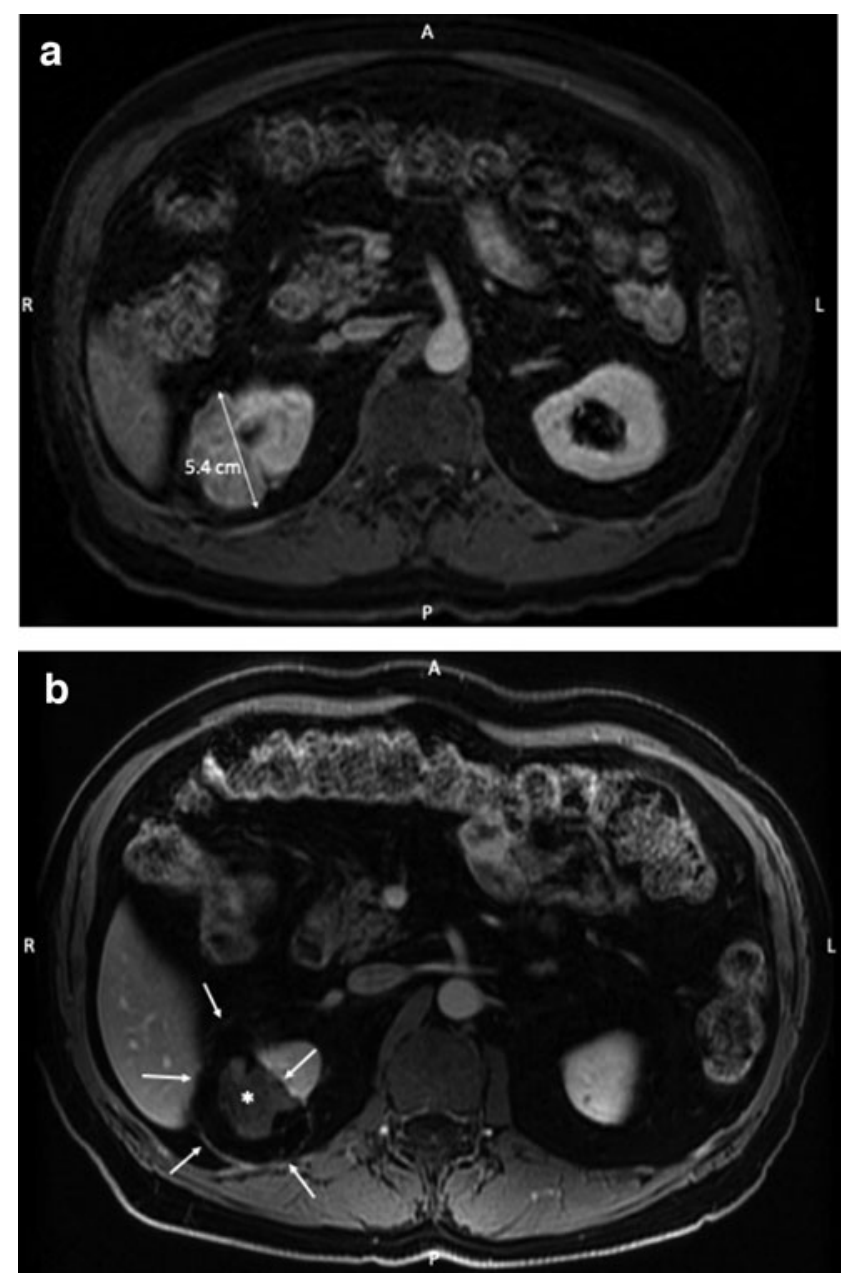

FIG. 1. Images of a 75-year-old man with right renal cell carcinoma. (a) Axial gadolinium-enhanced T1-weighted MRI of the abdomen shows a $5.4 \mathrm{~cm}$ exophytic tumor. (b) Axial gadolinium enhanced T1-weighted MRI shows no enhancement within the zone of ablation 12 months $\mathrm{s} / \mathrm{p}$ treatment with CT-guided microwave ablation. White arrows delineate the zone of ablation. White asterisk indicates treated tumor. 
FIG. 2. Kaplan-Meier curve demonstrating local tumor progression-free survival.

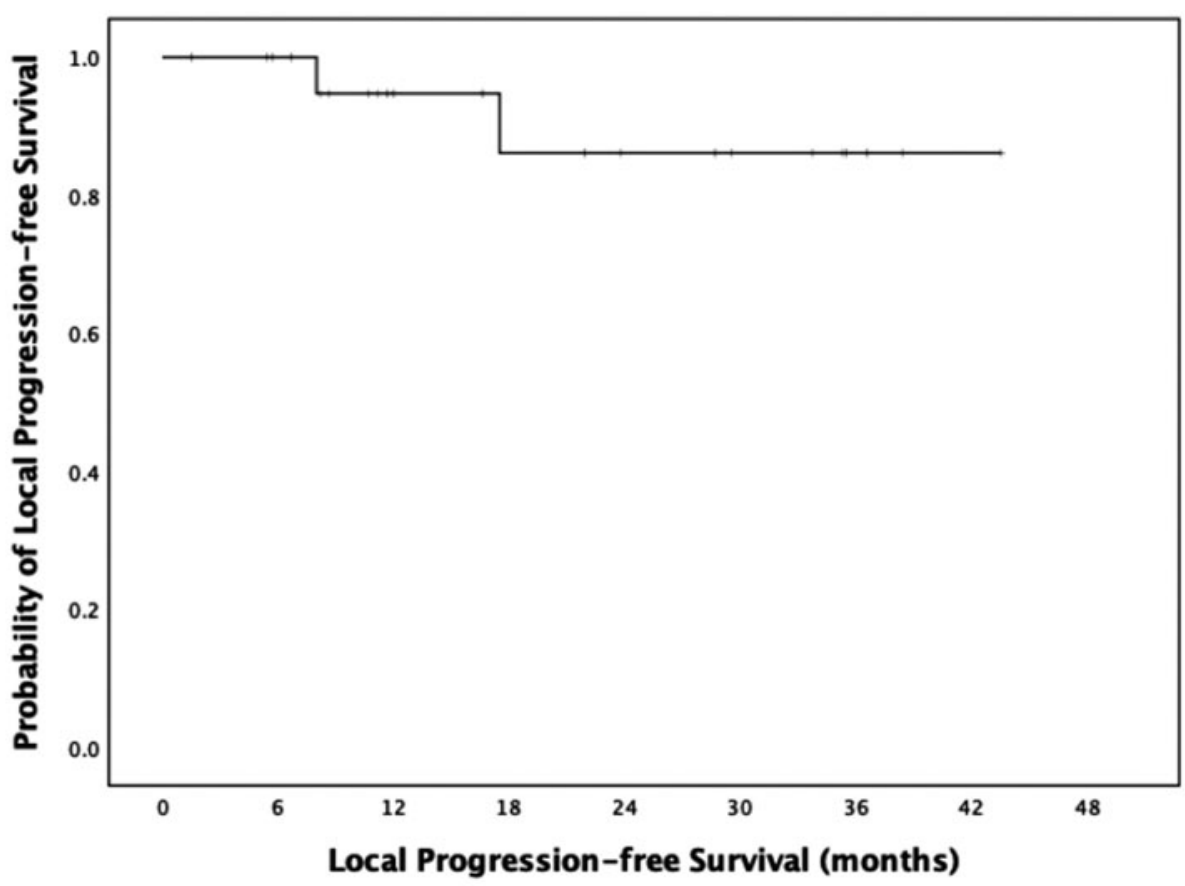

$\begin{array}{llllllllllll}\text { No. at risk } & 23 & 20 & 13 & 10 & 8 & 6 & 3 & 1 & 0 & 0\end{array}$ and $90.9 \%$, respectively (Fig. 2). The 1-, 2-, and 3-year OS was $95.2 \%, 85.7 \%$, and $71.4 \%$, respectively (Fig. 3 ).

\section{Complications}

There were $2 / 23(8.7 \%)$ minor complications (Class A and B). One patient developed an asymptomatic subcap- sular hematoma, which was identified on the first CT scan 1 month after the procedure. The other patient who was on coumadin for atrial fibrillation developed a retroperitoneal hematoma within 24 hours after the ablation procedure and was admitted overnight for hemodynamic monitoring, as well as pain and blood pressure control. There were no class $\mathrm{C}-\mathrm{F}$ complications.
FIG. 3. Kaplan-Meier curve demonstrating overall survival.

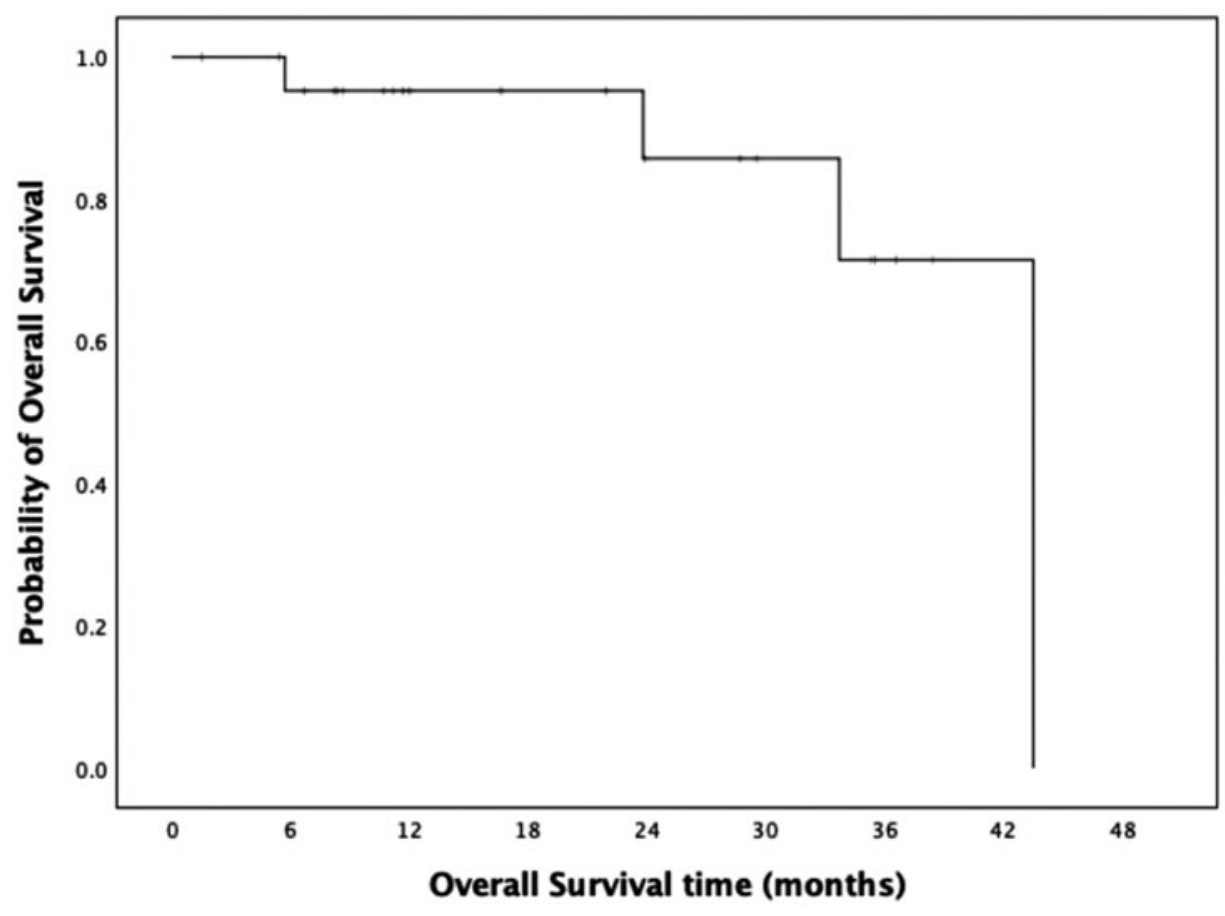


Table 2. Tumor Complexity (R.E.N.A.L. Score): Ablation Protocol and Clinical Results

\begin{tabular}{|c|c|c|c|c|}
\hline \multirow[b]{2}{*}{ Variable } & \multicolumn{3}{|c|}{ Total R.E.N.A.L. score } & \multirow[b]{2}{*}{$\mathrm{p}$} \\
\hline & $\begin{array}{c}\text { Low }(4-6) \\
(\mathrm{n}=6)\end{array}$ & $\begin{array}{l}\text { Moderate (7-9) } \\
\quad(\mathrm{n}=13)\end{array}$ & $\begin{array}{l}\operatorname{High}(10-12) \\
\quad(\mathrm{n}=4)\end{array}$ & \\
\hline Tumor diameter $(\mathrm{cm})$, mean $\pm \mathrm{SD}$ & $5.0 \pm 1.1$ & $5.4 \pm 0.9$ & $4.9 \pm 0.8$ & $0.452^{\mathrm{a}}$ \\
\hline Preablation tumor volume $\left(\mathrm{cm}^{3}\right)$, mean \pm SD & $57.7 \pm 32.6$ & $57.9 \pm 29.7$ & $44.7 \pm 29.7$ & $0.825^{\mathrm{a}}$ \\
\hline Postablation tumor volume $\left(\mathrm{cm}^{3}\right)$, mean \pm SD & $50.6 \pm 38.3$ & $47.3 \pm 38.5$ & $28.2 \pm 20.4$ & $0.605^{\mathrm{a}}$ \\
\hline No. of overlapping, median (range) & $3(1-5)$ & $4(1-8)$ & $2(1-3)$ & $0.152^{\mathrm{b}}$ \\
\hline Output power (W), median (range) & $60(40-80)$ & $60(40-80)$ & $60(60-80)$ & $0.439^{\mathrm{b}}$ \\
\hline Total ablation time (minutes), median (range) & $25(6-70)$ & $25(15-47)$ & $16.5(11-30)$ & $0.453^{b}$ \\
\hline Local tumor progression, $n(\%)$ & $0(0)$ & $0(0)$ & $1(25.0)$ & $0.083^{\mathrm{c}}$ \\
\hline Complications, $n(\%)$ & $0(0)$ & $2(15.4)$ & $0(0)$ & $0.431^{\mathrm{c}}$ \\
\hline
\end{tabular}

${ }^{\mathrm{a}}$ Compared using one-way analysis of variance test.

${ }^{\mathrm{b}}$ Compared using nonparametric two-independent samples test.

${ }^{\mathrm{c} C o m p a r e d ~ u s i n g} \chi^{2}$ test.

\section{Tumor complexity analysis}

Based on R.E.N.A.L and PADUA scores, there were similarities in the percentages of low complexity ( $26.1 \%$ vs $21.7 \%)$, moderate complexity $(56.6 \%$ vs $52.2 \%)$, or high complexity (1724\% vs $26.1 \%$ ) tumors, respectively. No significant differences were noted with regard to tumor diameter and pre- and postablation tumor volumes between low, moderate, and high complexity tumors with either scoring system. Similarly, no differences between R.E.N.A.L. and PADUA scores were noted in terms of number of overlapping ablation, generator output, tumor ablation time, complication rates, or local tumor progression (Tables 2 and 3).

\section{Discussion}

The results of the present study show overall favorable oncologic outcomes for patients with T1b RCC treated with CT-guided percutaneous MWA. The local tumor progressionfree survival reported in the present study of $100.0 \%, 90.9 \%$, and $90.9 \%$ at 1-, 2-, and 3-year follow-up compare favorably with a cohort of nine patients with $\mathrm{T} 1 \mathrm{~b}$ RCC treated with percutaneous MWA reported by Wells and colleagues, who found no short-term local tumor progression. ${ }^{17}$ Similarly, Gao and colleagues evaluated the efficacy of ultrasound guided percutaneous MWA of RCC adjacent to the renal sinus, in- cluding $12 \mathrm{~T} 1 \mathrm{~b}$ tumors. ${ }^{18}$ The results of that study found that the estimated 1-, 3-, and 5-year disease-free survival was $97.0 \%, 81.8 \%$, and $70.0 \%$, respectively, ${ }^{18}$ which are similar to results reported in the present study. In addition, the 1-, 2-, and 3 -year OS was $95.2 \%, 85.7 \%$, and $71.4 \%$, respectively, in the study. Compared to CA for T1b RCC, the results of the present study show similar short-term local tumor control rates, ${ }^{19-21}$ suggesting that MWA is as effective as the more commonly reported CA for T1b RCC.

Radical nephrectomy remains the standard of care for treatment of T1b RCC [20=2]. The present study also compares favorably to reported $94 \%$ recurrence-free survival with nephron sparing surgery or laparoscopic $\mathrm{RN}^{22-24}$

The results of the present study suggest that MWA may be a viable treatment option for larger renal tumors. Thermal ablation of T1b tumors is currently not recommended by available guidelines due to concerns of higher rates of local recurrence than $\mathrm{PN}^{3,25-27}$

The American and European Urological Associations only advise RFA or CA as an alternate therapy only for unfit surgery patients with $\mathrm{T} 1 \mathrm{~b} \mathrm{RCC}$ because of local recurrence following percutaneous treatment. ${ }^{3,28}$ A previously published randomized controlled trial comparing open $\mathrm{PN}$, laparoscopic PN, open MWA, and laparoscopic MWA showed that there was no difference in local recurrence-free survival with fewer

Table 3. Tumor Complexity (PADuA score): Ablation Protocol and Clinical Results

\begin{tabular}{|c|c|c|c|c|}
\hline \multirow[b]{2}{*}{ Variable } & \multicolumn{3}{|c|}{ Total PADUA score } & \multirow[b]{2}{*}{$\mathrm{p}$} \\
\hline & $\begin{array}{c}\text { Low }(6-7) \\
(\mathrm{n}=5)\end{array}$ & $\begin{array}{l}\text { Moderate (8-9) } \\
\quad(\mathrm{n}=12)\end{array}$ & $\begin{array}{l}\operatorname{High}(10-14) \\
\quad(\mathrm{n}=6)\end{array}$ & \\
\hline Tumor diameter $(\mathrm{cm})$, mean $\pm \mathrm{SD}$ & $5.1 \pm 1.2$ & $5.4 \pm 0.8$ & $4.9 \pm 0.9$ & $0.500^{\mathrm{a}}$ \\
\hline Preablation tumor volume $\left(\mathrm{cm}^{3}\right)$, mean \pm SD & $57.7 \pm 32.6$ & $59.2 \pm 24.9$ & $47.0 \pm 36.7$ & $0.828^{\mathrm{a}}$ \\
\hline Postablation tumor volume $\left(\mathrm{cm}^{3}\right)$, mean \pm SD & $50.6 \pm 38.3$ & $44.7 \pm 25.0$ & $39.0 \pm 50.8$ & $0.874^{\mathrm{a}}$ \\
\hline Number of overlapping, median (range) & $3(1-5)$ & $3(1-8)$ & $3(2-4)$ & $0.898^{\mathrm{b}}$ \\
\hline Output power $(\mathrm{W})$, median (range) & $60(40-80)$ & $70(40-80)$ & $60(60-80)$ & $0.377^{\mathrm{b}}$ \\
\hline Total ablation time (minutes), median (range) & $25(6-70)$ & $22.5(15-45)$ & $27(11-47)$ & $0.755^{\mathrm{b}}$ \\
\hline Local tumor progression, $n(\%)$ & $0(0)$ & $0(0)$ & $1(16.7)$ & $0.227^{\mathrm{c}}$ \\
\hline Complications, $n(\%)$ & $0(0)$ & $2(16.7)$ & $0(0)$ & $0.366^{\mathrm{c}}$ \\
\hline
\end{tabular}

${ }^{\mathrm{a} C}$ Compared using one-way analysis of variance test.

${ }^{\mathrm{b}}$ Compared using nonparametric two-independent samples test.

${ }^{c}$ Compared using $\chi^{2}$ test. 
complications with MWA compared to $\mathrm{PN}^{29}$ The present study suggests that similar outcomes may be achieved with the less invasive means of percutaneous access and faster recovery times. Comparison between $\mathrm{PN}$ and percutaneous MWA is difficult. However, local recurrence rates may not reduce the application of MWA for larger renal tumors, because repetitive ablation can improve efficiency and reduce the local recurrence-free rates. A recent meta-analysis showed that repetitive ablation could significantly improve the recurrence-free survival of thermal ablation compared to $\mathrm{PN}^{30}$

While MWA of T1b RCC can present more technical challenges based on tumor size, the present study shows that percutaneous CT-guided MWA of larger tumors can achieve a high rate of technical success (100\%). In addition, the number of overlapping ablations, generator output, duration of ablation, local tumor progression rates, and complication rates were similar for low, moderate, and high tumor complexity in our study. The results of this study show that MWA is likely less affected by tumor size and complexity compared with RFA and CA. As reported in previous studies, there were many factors that may affect the technical success of RFA and CA, such as tumor size, location and relationship with renal sinus, and collecting system. ${ }^{31,32}$ Some studies suggest that RFA and CA may be associated with more technical failure for treatment of larger tumors or more complex tumors. ${ }^{32,33}$

The present study also found that the postablation tumor volume was significantly smaller than the preablation tumor volume. The presumed reasons are dehydration and collagen shrinkage in the tumors. Fewer complications may be an advantage of percutaneous MWA, compared with more invasive techniques. ${ }^{34}$ In the present study, the overall rate of complications was not affected by tumor size or complexity.

There are also some limitations in the present study. First, the retrospective and single-center nature of this study is a limitation associated with inevitable technical and personnel bias. This is compounded by the use of a single manufacturer; thus, the results may not be generalizable to all microwave devices. Second, even though this study achieved good clinical and technique outcomes, it is still limited by a small sample size. Third, the small sample size limits that strength of the complexity analysis. A larger cohort would be required to further assess the impact of tumor complexity on outcomes. Furthermore, the short-term follow-up and noncontrol design were limited to assess the long-term clinical outcomes and objective efficacy compared with other options.

\section{Conclusion}

This study shows that CT-guided percutaneous MWA shows good oncologic outcomes and is associated with few complications when used to treat cT1b RCC. While these results are encouraging, additional clinical trials are necessary to carefully evaluate the long-term clinical and oncologic outcomes, as well as safety, to better define this technology as a potential thermal ablation option for treatment of cT1b RCC.

\section{Author Disclosure Statement}

No competing financial interests exist.

\section{Funding Information}

No funding was provided for this article.

\section{References}

1. Ferlay J, Colombet M, Soerjomataram I, Mathers C, Parkin $\mathrm{DM}$, Piñeros $\mathrm{M}$, et al. Estimating the global cancer incidence and mortality in 2018: GLOBOCAN sources and methods. Int J Cancer 2019;144:1941-1953.

2. Zondervan PJ, Bujis M, DeBruin DM, van Delden OM, Van Lienden KP. Available ablation energies to treat ct1 renal cell cancer: Emerging technologies. World J Urol 2019;37:445-455.

3. Campbell S, Uzzo RG, Allaf ME, Bass EB, Cadeddu JA, Chang A, et al. Renal mass and localized renal cancer: AUA guideline. J Urol 2017;198:520-529.

4. Thompson RH, Atwell T, Schmit G, et al. Comparison of partial nephrectomy and percutaneous ablation for cT1 renal masses. Eur Urol 2015;67:252-259.

5. Yang Y, Chen S, Chen F, Zhu K, Deng Q, Luo L, et al. Outcome of radiofrequency ablation over partial nephrectomy for small renal mass $(<4 \mathrm{~cm})$ : A systematic review and meta-analysis. Int J Clin Exp Med 2015;8:20670-20674.

6. Best SL, Park SK, Youssef RF, Olweny EO, Tan YK, Trimmer $\mathrm{C}$, et al. Long-term outcomes of renal tumor radio frequency ablation stratified by tumor diameter: Size matters. J Urol 2012;187:1183-1189.

7. Hasegawa T, Yamanaka T, Gobara H, Miyazaki M, Takaki $\mathrm{H}$, Sato $\mathrm{Y}$, et al. Radiofrequency ablation versus cryoablation for T1b renal cell carcinoma: A multi-center study. Jpn J Radiol 2018;36:551-558.

8. Welch BT, Shah PH, Thompson RH, Atwell TD. The current status of thermal ablation in the management of T1b renal masses. Int J Hyperthermia 2019;36:31-36.

9. Thompson SM, Schmitz JJ, Thompson RH, et al. Introduction of microwave ablation into a renal ablation practice: Valuable lessons learned. AJR Am J Roentgenol 2018;211:1381-1389.

10. Arellano RS, Garicai RG, Gervais DA, Mueller PR. Percutaneous CT-guided radiofrequency ablation of renal cell carcinoma: Efficacy of organ displacement by injection of $5 \%$ dextrose in water into the retroperitoneum. AJR Am J Roentgenol 2009;193:1686-1690.

11. Dai Y, Covarrubias D, Uppot R, Arellano RS. Image-guided percutaneous radiofrequency ablation of central renal cell carcinoma: Assessment of clinical efficacy and safety in 31 tumors. J Vasc Interv Radiol 2017;28:1643-1650.

12. Charlson M, Szatrowski TP, Peterson, Gold J. Validation of a combined comorbidity index. J Clin Epidemiol 1994;47: 1234-1251.

13. Kutikov A, Uzzo RG. The R.E.N.A.L. nephrometry score: A comprehensive standardized system for quantitating renal tumor size, location and depth. J Urol 2009;182: 844-853.

14. Ficarra V, Novara G, Secco S, Macchi V, Porzionato A, De Caro R, et al. Preoperative aspects and dimensions used for an anatomical (PADUA) classification of renal tumours in patients who are candidates for nephron-sparing surgery. Eur Urol 2009;56:786-793.

15. Khalilzadeh O, Baerlocher MO, Shyn PB, Connolly BL, Devane AM, Morris CS, et al. Proposal of a new adverse event classification by the society of interventional radiology standards of practice committee. J Vasc Interv Radiol 2017;28:1432-1437. 
16. Ahmed M; Technology Assessment Committee of the Society of Interventional Radiology. Image-guided tumor ablation: Standardization of terminology and reporting criteria-A 10-year update: Supplement to the consensus document. J Vasc Interv Radiol 2014;25:1706-1708.

17. Wells SA, Wheeler KM, Mithqal A, Patel MS, Brace CL, Schenkman NS. Percutaneous microwave ablation of T1a and $\mathrm{T} 1 \mathrm{~b}$ renal cell carcinoma: Short-term efficacy and complications with emphasis on tumor complexity and single session treatment. Abdom Radiol (NY) 2016;41: 1203-1211.

18. Gao Y, Liang P, Yu X, Yu J, Cheng Z, Han Z, et al. Microwave treatment of renal cell carcinoma adjacent to renal sinus. Eur J Radiol 2016;85:2083-2089.

19. Rodriguez R, Cizman Z, Hong K, Koliatsos A, Georgiades C. Prospective analysis of the safety and efficacy of percutaneous cryoablation for pT1NxMx biopsy-proven renal cell carcinoma. Cardiovasc Intervent Radiol 2011;34:573-578.

20. Grange R, Tradi F, Izaaryene J, Nassima D, Serge B, Walz J, et al. Computed tomography-guided percutaneous cryoablation of T1b renal tumors: Safety, functional and oncological outcomes. Int J Hyperthermia 2019;36:1065-1071.

21. Atwell TD, Vlaminck JJ, Boorjian SA, Kurup AN, Callstrom MR, Weisbrod AJ, et al. Percutaneous cryoablation of stage T1b renal cell carcinoma: Technique, considerations, safety and local tumor control. J Vasc Interv Radiol 2015;26:792-799.

22. Badalato GM, Kates M, Wisnivesky JP, Choudhury AR, McKiernan JM. Survival after partial and radical nephrectomy for the treatment of stage T1bN0M0 renal cell carcinoma (RCC) in the USA: A propensity scoring approach. BJU Int 2012;109:1457-1462.

23. Leibovich BC, Blute M, Cheville JC, Lohse CM, Weaver AL, Zincke H. Nephron sparing surgery for appropriately selected renal cell carcinoma between 4 and $7 \mathrm{~cm}$ results in outcome similar to radical nephrectomy. J Urol 2004;171: 1066-1070.

24. Simmons MN, Weight CJ, Gill IS. Laparoscopic radical versus partial nephrectomy for tumors $>4 \mathrm{~cm}$ : Intermediateterm oncologic and functional outcomes. Urology 2009;73: 1077-1082.

25. Hui GC, Tuncali K, Tatli S, Morrison PR, Silverman SG. Comparison of percutaneous and surgical approaches to renal tumor ablation: Metaanalysis of effectiveness and complication rates. J Vasc Interv Radiol 2008;19:1311-1320.

26. Balageas P, Cornelis F, Le Bras Y, Hubrecht R, Bernhard JC, Ferrière JM, et al. Ten-year experience of percutaneous image-guided radiofrequency ablation of malignant renal tumours in high-risk patients. Eur Radiol 2013;23:1925-1932.

27. Psutka SP, Feldman AS, McDougal WS, McGovern FJ, Mueller P, Gervais DA. Long-term oncologic outcomes after radiofrequency ablation for $\mathrm{T} 1$ renal cell carcinoma. Eur Urol 2013;63:486-492.

28. Ljungberg B, Bensalah K, Canfield S, Dabestani S, Hofmann F, Hora M, et al. EAU guidelines on renal cell carcinoma: 2014 update. Eur Urol 2015;67:913-924.

29. Guan W, Bai J, Liu J, Wang S, Zhuang Q, Ye Z, et al. Microwave ablation versus partial nephrectomy for small renal tumors: Intermediate-term results. J Surg Oncol 2012; 106:316-321.

30. Pierorazio PM, Johnson MH, Patel HD, Sozio SM, Sharma $\mathrm{R}$, Lyoha E, et al. Management of renal masses and localized renal cancer: Systematic review and meta-analysis. J Urol 2016;196:989-999.

31. Schmit GD, Thompson RH, Kurup AN, Weisbrod AJ, Boorjian SA, Carter RE, et al. Usefulness of R.E.N.A.L. nephrometry scoring system for predicting outcomes and complications of percutaneous ablation of 751 renal tumors. J Urol 2013;189:30-35.

32. McClure TD, Chow DS, Tan N, Sayre JA, Pantuck AJ, Raman SS. Intermediate outcomes and predictors of efficacy in the radiofrequency ablation of 100 pathologically proven renal cell carcinomas. J Vasc Interv Radiol 2014;25: 1682-8; quiz 1689.

33. Camacho JC, Kokabi N, Xing M, Master VJ, Pattaras JG, Mittal PK, et al. R.E.N.A.L. (Radius, exophytic/endophytic, nearness to collecting system or sinus, anterior/posterior, and location relative to polar lines) nephrometry score predicts early tumor recurrence and complications after percutaneous ablative therapies for renal cell carcinoma: A 5-year experience. J Vasc Interv Radiol 2015;26:686-693.

34. Chan P, Vélasco S, Vesselle G, Boucebci S, Herpe G, Debaene B, et al. Percutaneous microwave ablation of renal cancers under CT guidance: Safety and efficacy with a 2year follow-up. Clin Radiol 2017;72:786-792.

Address correspondence to: Ronald S. Arellano, MD Division of Interventional Radiology Department of Radiology Massachusetts General Hospital 55 Fruit Street, GRB 293 Boston, MA 02114 USA

E-mail: rarellano@mgh.harvard.edu

Abbreviations Used
$\mathrm{CA}=$ cryoablation
$\mathrm{CT}=$ computed tomography
$\mathrm{MRI}=$ magnetic resonance imaging
$\mathrm{MWA}=$ microwave ablation
$\mathrm{OS}=$ overall survival
PADUA $=$ preoperative aspects and dimensions used
$\quad$ for an anatomical
$\mathrm{PN}=$ partial nephrectomy
R.E.N.A.L. $=$ Radius, Exophytic/Endophytic, Nearness to
$\quad$ the collecting system, Anterior/posterior,
Location relative to the polar lines
$\mathrm{RFA}=$ renal cell carcinoma
$\mathrm{RN}=$ radiofrequency ablation
$\mathrm{SD}=$ radical nephrectomy

